\title{
Three major works in the humanities and social sciences coming from Vietnam
}

\author{
Tam-Tri Le \\ April 14, 2021

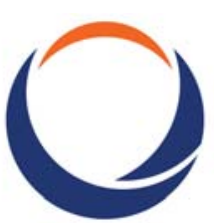 \\ PHENIKAA \\ UNIVERSITY
}

They are research studies on the intersection of several fields in the humanities and social sciences, namely social anthropology, linguistics, folkloristics, applied Bayesian statistics, and cultural studies (see the references). All these three studies have been conducted by the Hanoi-based ISR research team at Phenikaa University, Ha Dong district, Hanoi, Vietnam.

All three studies have demonstrated the usefulness and efficiencies of Bayesian statistical analysis. But they are far from just pieces of dry prose or number-crunching. Whenever possible, the authors use artworks to make their scientific exploration more compelling and convincing.

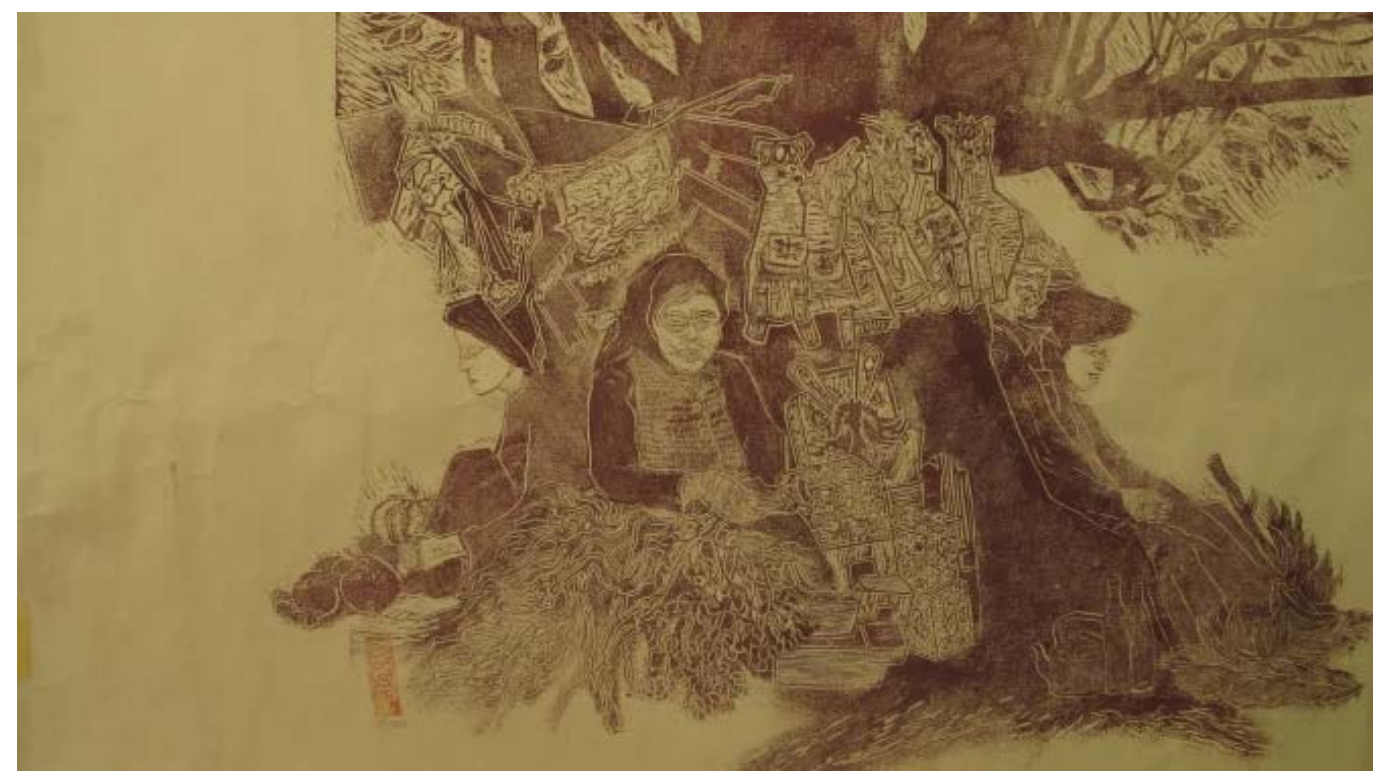

The artwork was used in one study while discussing the implications and usefulness of the cultural additivity concept (Vuong et al., 2018). 
They extensively use the graphical power provided by the Bayesian approach. Two of them benefit from the utilities supplied by the bayesvl R package.

All three publications have contributed significantly to the academic literature by bringing up new understandings with plausible reasoning and will likely have a long-term impact on subsequent studies in the related fields. In fact, the first of them published in 2018 has gained increasing attention from the scholarly communities as well as the wider public.

One of the most notable features of these research studies is that none of them have incurred a large data cost issue to the research program. In addition, their data are, generally speaking, ageless.

It can be hoped that these works will be able to show their long-term value and far-reaching effect on the understanding of society as well as benefit future works by other scholars in the HSS.

\section{References}

Vuong, Q. H., et al. (2018). Cultural additivity: behavioural insights from the interaction of Confucianism, Buddhism and Taoism in folktales. Palgrave Communications, 4(1), 143.

Vuong, Q. H., et al. (2019). Cultural evolution in Vietnam's early 20th century: A Bayesian networks analysis of Hanoi Franco-Chinese house designs. Social Sciences \& Humanities Open, 1(1), 100001.

Vuong, Q. H., et al. (2020). On how religions could accidentally incite lies and violence: Folktales as a cultural transmitter. Palgrave Communications, 6(1), 82. 